\title{
"RENCANA STRATEGI BENDUNG KARET BERISI AIR SEBAGAI INOVASI TEPAT GUNA DALAM PENANGGULANGAN BANJIR DAN ROB“"
}

\author{
Fatchur Roehman, ST. MT \\ Dosen Teknik Sipil, Fakultas Teknik, Universitas Sultan Fatah Demak, \\ fatchurroehman@gmail.com, Jl. Raya Katonsari No. 19 Demak
}

\begin{abstract}
Abstrak
Di Indonesia banyak terdapat sumberdaya air, tentu saja tidak mudah untuk mengolah sumberdaya tersebut, misalnya masalah banjir dan rob di Kota Semarang, ketika musim hujan air disungai tidak dapat mengalir ke laut karena air pasang / rob yang masuk melalui muara sungai, sehingga meyebabkan banjir. Perumusan masalah dalam penelitian ini memahami bagaimana efektivitas bendung karet isi air dari aspek hidrolik, karakteristik material bendung serta analisis stabilitas terhadap model numerik.

Maksud dan tujuan penelitian adalah menganalisa efektivitas hidrolik bendung karet isi air dalam stabiltas menahan beban aliran, menganalisis karakteristik material sehingga didapatkan material bendung yang baik.

Metode yang digunakan dengan beberapa variasi simulasi model telah dilakukan untuk mencari korelasi antara elevasi permukaan air di hulu dari (10 $\mathrm{cm}$ sampai dengan 40 $\mathrm{cm})$ dan simulasi elevasi dihilir $(1 \mathrm{~cm}$ sampai $4 \mathrm{~cm}$ ) variabel yang dikaji diantaranya beban sendiri bendung, tekanan lumpur, gempa, hidrostatis harapannya dihasilkan semakin tinggi safety faktor yang terjadi maka akan kuat bendung menahan terhadap gaya guling.

Hasil sementara uji laboratorium yang diperoleh pada elevasi dihulu $40 \mathrm{~cm}$ dan di hilir $25 \mathrm{~cm}$ maka didapatkan berat bendung sendiri yang mampu menahan gaya dari hulu 0,155 (Ton.Meter), gaya hidrostatis 0,084 (Ton.Meter) sehingga bendung dengan berat sendiri mampu menahan gaya stabilitas dan mampu menahan gaya guling sehingga bendung tidak bergeser.
\end{abstract}

Kata kunci: bendung karet isi air, inovasi, penanggulangan banjir dan rob

\section{Latar Belakang}

Kebijakan pemerintah dalam upaya mengatasi banjir dan rob telah banyak dilakukan, yakni dengan membangun infrastruktur fisik seperti jalan, drainase, polder, serta infrastruktur pendukung lainnya. Namun upaya tersebut hingga kini belum sepenuhnya dirasakan manfaatnya oleh masyarakat. Penanggulangan banjir dan rob bendung karetisi air memang segera terselesaikan. Material yang digunakan merupakan teknologi tepat guna sehingga masyarakat mudah untuk mendapatkan serta operasionalnya. Masyarakat agar turut serta membantu menjaga bendungan yang telah dibuat sehingga permukiman dan jalan sekitarnya tidak tergenang banjir (Roehman F, 2017) [15].

Tindakan-tindakan yang dapat dilakukan untuk pengendalian banjir antara lain: Pengurangan puncak banjir, yang ada pada umumnya dengan membuat reservoir (waduk); Lokalisir aliran banjir di dalam alur sungai yang ditetapkan dengan tanggul, tembok banjir atau saluran 
tertutup; Penurunan permukaan puncak banjir dengan menaikkan besarnya kecepatan air, yaitu dengan perbaikan alur; Pengalihan air banjir melalui sudetan atau saluran banjir (floodway) ke dalam alur sungai atau bahkan ke daerah aliran sungai lain; Pengurangan limpasan banjir dengan pengolajhan lahan; Pengolahan daratan banjir [11].

\section{Maksud dan Tujuan}

Untuk tujuan penelitian ini adalah menganalisis efektivitas hidrolik bendung karet isi air, karakteristik material bendung, analisis stabilitas pada model bendung karet isi air[14].

\section{Perumusan Masalah}

Pada penelitian ini yang akan dikaji adalah (1). bagaimana efektivitas bendung karet isi air dari aspek hidrolik? (2) bagaimana karakteristik material bendung karet isi air? (3) Bagaimana analisis stabilitas terhadap model numerik terhadap bendung karet isi air? [14].

\section{Kajian Pustaka}

Bendung (Weir) adalah Konstruksi Bangunan Air yang melintang sungai yang bertujuan untuk menaikkan muka air sungai di Upstream. Tujuan selebihnya adalah dengan naiknya muka air sehingga akan dapat digunakan untuk mengairi sawah (irigasi). Bendung Gerak (Barrage), merupakan bendung dengan elevasi mercu yang tidak tetap (bisa digerakkan), atau dilengkapi dengan alat pengatur / pintu, sehingga dapat mengatur elevasi muka air. Alat pengatur dari Bendung Karet, dapat dikembang kempiskan sesuai kebutuhan, yaitu dengan menambah atau mengurangi isinya. Isi Bendung karet bisa dari air atau udara [13].

Acuan normatif dalam perencanaan bendung karet dapat gunakan diantaranya SNI 03-2415-1991 tentang Metode perhitungan debit banjir, SNI 03-17241989 tentang Pedoman perencanaan hidrologi dan hidraulika untuk bangunan di sungai, SNI 03-2401-1991 tentang Tata cara perencanaan bendung [17].

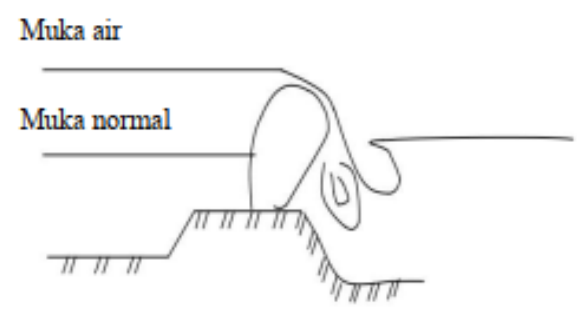

\section{Gambar 1. Pola Bendung Karet Isi Udara} Dedi Tjahjadi Abdullah, 1999

Acuan normatif dalam perencanaan bendung karet dapat gunakan diantaranya SNI 03-2415-1991 tentang Metode perhitungan debit banjir, SNI 03-17241989 tentang Pedoman perencanaan hidrologi dan hidraulika untuk bangunan di sungai, SNI 03-2401-1991 tentang Tata cara perencanaan bendung [17].

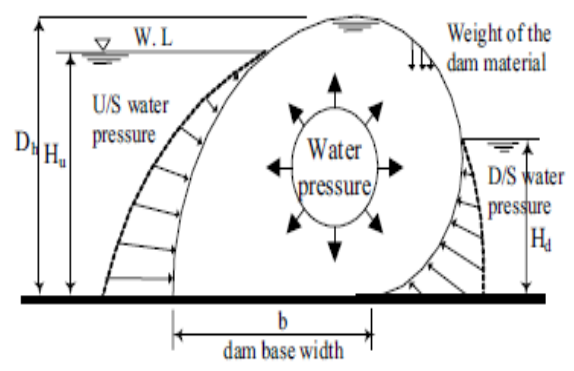

Gambar 2. Sistem tekanan air di bendung (Abdullah Ali Nasser Alhamati dkk,2005)

Bendungan inframerah adalah struktur karet tiup silinder fleksibel dan mudah dilipat yang terbuat dari bahan karet dilekatkan pada dasar yang kaku dan digelembungkan oleh udara, air, atau kombinasi udara / air. [17].

Secara hidraulik bendung karet harus mampu melayani taraf muka air yang direncanakan; dapat membuka secara otomatis jika terjadi banjir yang melampaui batas tertentu; pada bendung yang berfungsi untuk menahan intrusi air asin, air asin yang terperangkap di hulu bendung harus bisa didorong ke hilir; aman terhadap gerusan dasar sungai akibat energi terjunan air; aman terhadap gangguan akibat arus air dan benda padat yang terangkut; tinggi 
bendung karet umumnya tidak melebihi $5,00 \mathrm{~m}$, dengan pertimbangan bahwa konstruksi bendung karet dengan tinggi $>5,00 \mathrm{~m}$ tidak efisien lagi. Secara struktural bendung karet harus memenuhi persyaratan kuat dan stabil terhadap penggulingan penggeseran dan batas daya dukung tanah serta erosi dasar fondasi. [11]. Bahan karet merupakan lembaran karet terbuat dari bahan karet asli atau sintetik yang elastik, kuat, keras, dan tahan lama. Pada umumnya bahan karet yang digunakan memiliki spesifikasi Kekerasan tes abrasi menggunakan metode $\mathrm{H} 18$ dengan beban 1 $\mathrm{kg}$ pada putaran !000 kali tidak melampaui $0,8 \mathrm{~m} 3 / \mathrm{mil}$, Kuat tarik pada suhu normal $\geq$ $150 \mathrm{~kg} / \mathrm{cm} 2$ dan kuat tarik pada suhu $100 \mathrm{o}$ $\geq 120 \mathrm{~kg} / \mathrm{cm} 2$. Bahan karet diperkuat dengan susunan benang nilon yang memberikan kekuatan tarik sesuai dengan yang dibutuhkan untuk menahan gaya. Bahan dasar karet umumnya digunakan karet sintetis seperti ethylene propylene diene monomer (EPDM), chloroprene rubber (CR). Kekuatan lembaran karet harus mampu menahan gaya tekanan air dikombinasikan dengan gaya tekanan udara dari dalam tubuh bendung. Gaya tersebut dapat dihitung dengan pendekatan sebagai berikut [17].

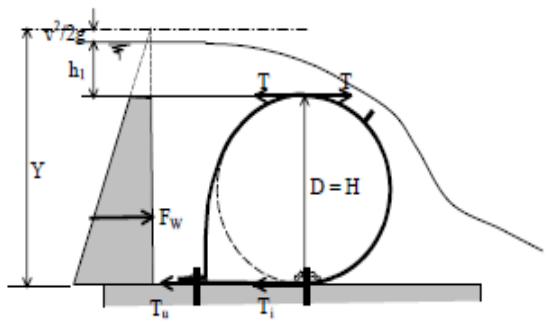

Gambar 3. Sketsa Gaya Tarik

(Badan Penerbit Pekerjaan Umum, 2005)

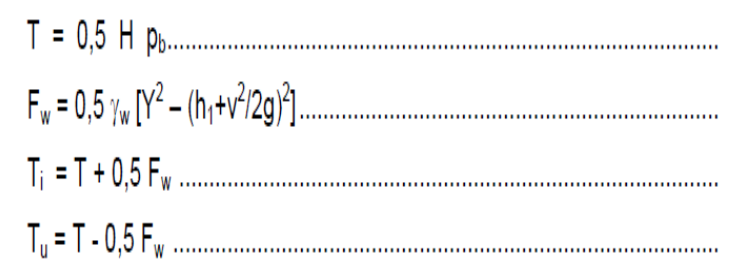

dengan:

$\mathrm{T}$ adalah gaya tarik pada selubung tabung karet $(\mathrm{N} / \mathrm{m})$
$\mathrm{H}$ adalah tinggi bendung (m)

$\mathrm{pb}$ adalah tekanan udara dalam tabung karet $(\mathrm{Pa})$

Fw adalah gaya tekanan air dari hulu pada tubuh bendung $(\mathrm{N} / \mathrm{m})$

$\gamma \mathrm{w}$ adalah berat jenis air, diambil 9810 $\mathrm{N} / \mathrm{m} 3$

Y adalah kedalaman air hulu bendung (m)

h1 adalah tinggi pembendungan maksimum (m)

v adalah kecepatan rata-rata aliran air di hulu bendung $(\mathrm{m} / \mathrm{s})$

g adalah gravitasi, diambil $9,81 \mathrm{~m} / \mathrm{s} 2$

Ti adalah gaya pada angker hilir $(\mathrm{N} / \mathrm{m})$

$\mathrm{Tu}$ adalah gaya pada angker hulu $(\mathrm{N} / \mathrm{m})$

Kekuatan tarik lembaran karet pada arah aliran air ditetapkan dengan rumus :

$\mathrm{KT}=\mathrm{n} \mathrm{Ti}$

dengan:

KT adalah kekuatan tarik karet searah aliran air $(\mathrm{N} / \mathrm{m})$

$\mathrm{n}$ adalah angka keamanan, diambil 8

Kekuatan tarik searah as bendung ditentukan sebesar 60\% KT.

\section{Bendung Karet Yang Sudah Ada di} Lapangan

\begin{tabular}{|c|c|c|c|c|c|c|}
\hline $\begin{array}{l}\mathbf{N} \\
\mathbf{0}\end{array}$ & $\begin{array}{l}\text { Nama } \\
\text { Bendu } \\
\text { ng }\end{array}$ & Lokasi & Sungai & $\begin{array}{l}\text { Lebar } \\
\text { Bendu } \\
\text { ng }\end{array}$ & $\begin{array}{l}\text { Tinggi } \\
\text { Bendu } \\
\text { ng }\end{array}$ & $\begin{array}{l}\text { Kap } \\
\text { asita } \\
\text { s } \\
\text { Tam } \\
\text { pung }\end{array}$ \\
\hline 1 & $\begin{array}{l}\text { Bendu } \\
\text { ng } \\
\text { Karet } \\
\text { Welah } \\
\text { an } \\
\text { Bum }\end{array}$ & $\begin{array}{l}\text { Desa } \\
\text { Gerdu, } \\
\text { Kec. } \\
\text { Pecang } \\
\text { aan, } \\
\text { Kab. } \\
\text { Jepara }\end{array}$ & $\begin{array}{l}\begin{array}{l}\text { Kali } \\
\text { Bum } \\
\text { (Sebela }\end{array} \\
\text { h } \\
\text { Timur } \\
\text { Sungai } \\
\text { Serang } \\
\text { ) }\end{array}$ & $\begin{array}{l}127,50 \\
\mathrm{~m} \\
(2 \times 30 \\
\mathrm{m})\end{array}$ & $3 \mathrm{~m}$ & $\begin{array}{l}2.62 \\
8.31 \\
9 \mathrm{~m} 3\end{array}$ \\
\hline 2 & $\begin{array}{l}\text { Bendu } \\
\text { ng } \\
\text { Karet } \\
\text { Buko } \\
\text { Kab } \\
\text { Demak }\end{array}$ & $\begin{array}{l}\text { J1 Raya } \\
\text { Buko- } \\
\text { Kendur } \\
\text { en Kec. } \\
\text { Wedun } \\
\text { g, Kab. } \\
\text { Demak }\end{array}$ & $\begin{array}{l}\text { Kali } \\
\text { Kumpu } \\
\text { lan }\end{array}$ & $42 \mathrm{~m}$ & $2,70 \mathrm{~m}$ & $\begin{array}{l}600 . \\
000 \\
\text { m3 }\end{array}$ \\
\hline 3 & $\begin{array}{l}\text { Bendu } \\
\text { ng } \\
\text { Karet } \\
\text { Kali } \\
\text { Jajar } \\
\text { Kab } \\
\text { Demak }\end{array}$ & $\begin{array}{l}\text { Desa } \\
\text { Jatirog } \\
\text { o, Kec. } \\
\text { Bonan } \\
\text { g, Kab. } \\
\text { Demak }\end{array}$ & $\begin{array}{l}\text { Kali } \\
\text { Jajar } \\
\text { Kab } \\
\text { Demak }\end{array}$ & $\begin{array}{l}75,5 \mathrm{~m} \\
(2 \times 37, \\
75 \mathrm{~m})\end{array}$ & $\begin{array}{l}3 \mathrm{~m}, \\
\text { lebar } \\
\text { isi } \\
\text { penuh } \\
5,5 \mathrm{~m} \text {, } \\
\text { tebal } \\
\text { karet } \\
10,5 \\
\mathrm{~mm}\end{array}$ & $\begin{array}{l}1.45 \\
0.00 \\
0 \mathrm{~m} 3\end{array}$ \\
\hline
\end{tabular}




\section{Tempat dan Waktu Penelitian}

Untuk tempat penelitian di Kota Semarang dan mengaplikasikan model Kanal Sirkuit Tertutup di Laboratorium Teknik Sipil Universitas Islam Sultan Agung (UNISSULA) SEMARANG dengan waktu empat bulan.

\section{Populasi dan Sampel}

Objek pada penelitian ini adalah menghitung debit air, dimensi bendung, stabilitas bendung dengan perilaku pembebanan dalam bendung yang berisi air dengan cepat dan benar, data yang diperlukan adalah gambar rencana dimensi dan konstruksi bendung karet isi air, debit air dan pendukung lainnya yang digunakan penelitian, stabilitas bendung karet isi air, persamaan rumus - rumus hidrolika yang digunakan penelitian, Rencana Anggaran Biaya yang digunakan penelitian, referensi pedoman DED bendung karet isi air, bahan dan Peralatan

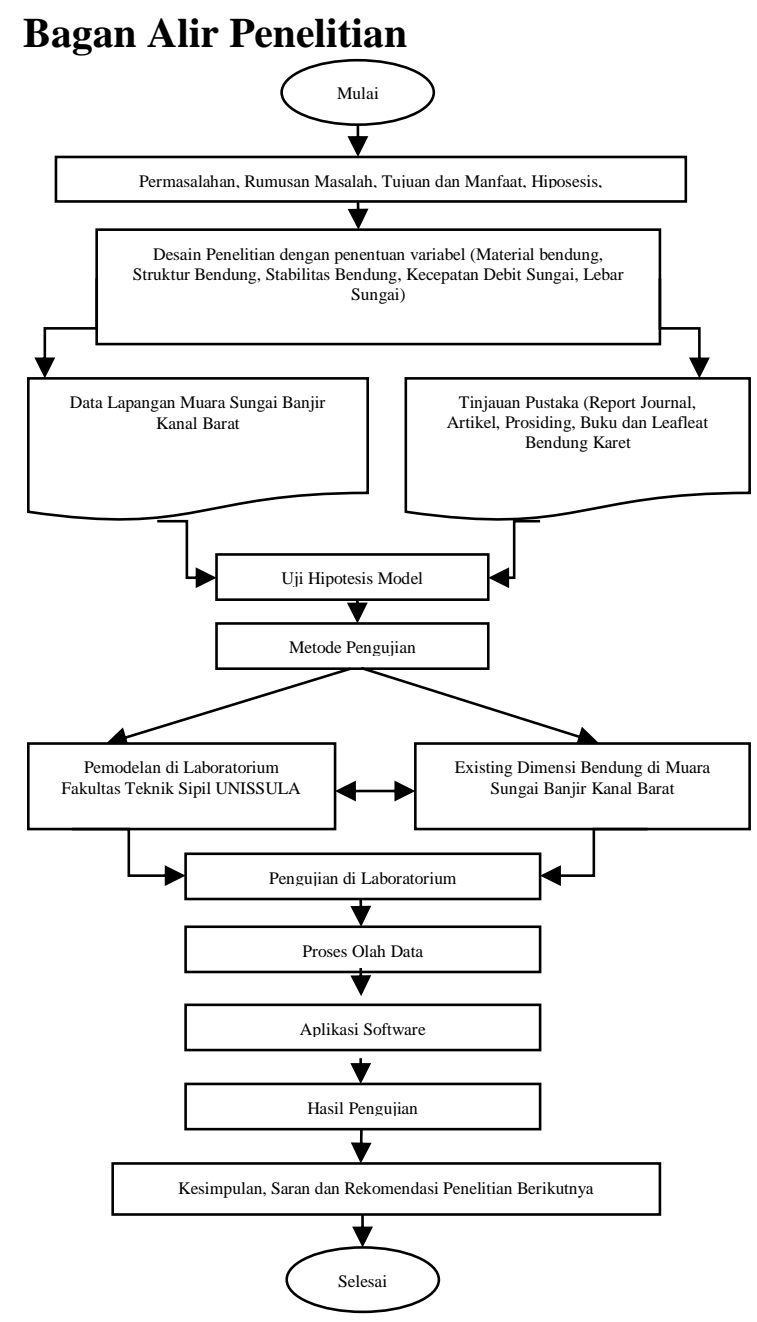

Gambar 4. Bagan Alir Penelitian

(Sumber : Proses di Laboratorium Peneliti Fatchur Roehman, 2019)

\section{Hasil Dan Pembahasan}

Bagian bendung terdiri dari beberapa komponen diantaranya Badan Bendung (Body of Dams) berfungsi sebagai penghalang air. Pondasi (Foundation) berfungsi untuk menjaga kokohnya bendung. Pintu Air (Gates) digunakan untuk mengatur, membuka dan menutup aliran air. Daun Pintu (Gate Leaf) yang menahan tekanan air dan dapat digerakan untuk membuka, mengatur, dan menutup aliran air. Rangka Pengatur Arah Gerakan (Guide Frame) menjaga agar gerakan dari daun pintu sesuai dengan yang direncanakan. Angker (Anchorage) untuk menahan rangka pengatur arah gerakan agar dapat memindahkan muatan dari pintu air ke dalam konstruksi beton. Hoist Alat untuk menggerakan daun pintu air agar dapat dibuka dan ditutup dengan mudah. Bangunan Pelimpah (Spill Way) untuk mengalirkan air banjir yang masuk ke dalam waduk agar tidak membahayakan keamanan bendungan.
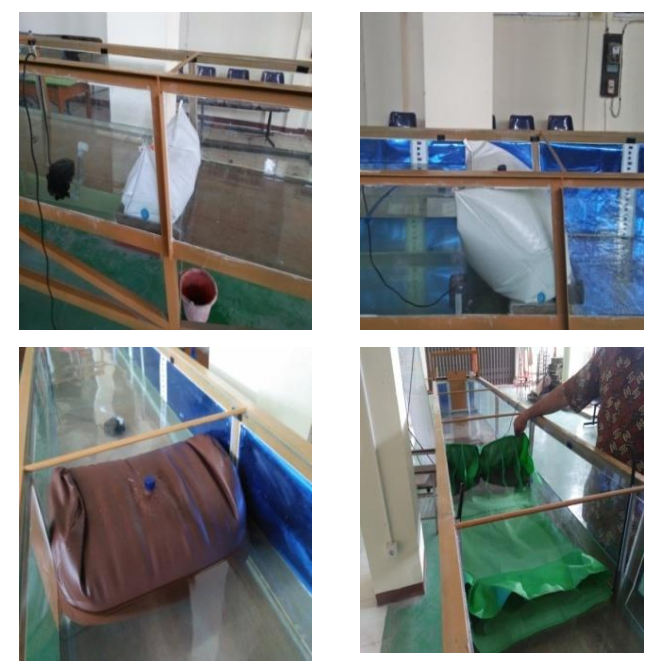

Gambar 5 : Bentuk Bendung Segitiga, Segi empat, Silinder, Trapesium (Sumber : Simulasi di Laboratorium Peneliti Fatchur Roehman, 2019) 


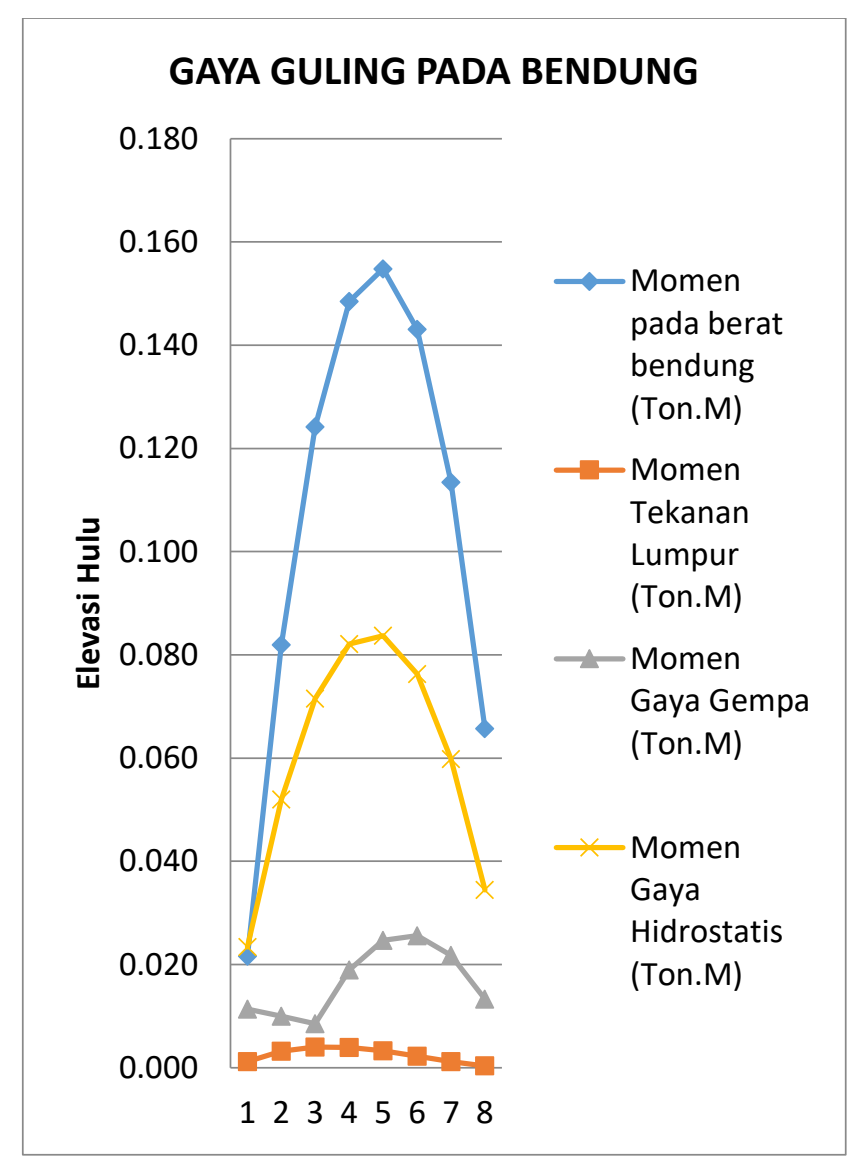

\section{Gambar 6 : Gaya Guling Bendung Hasil Simulasi}

(Sumber : Pengolahan Hasil Simulasi, Peneliti Fatchur Roehman, 2019)

\section{Analisa Kriteria Bendung yang Baik.}

Mempunyai kriteria bisa menahan gaya guling, dikembangkan dengan baik tanpa mengalami kebocoran, bisa mengempis secara otomatis dan manual pada kondisi yang direncanakan bersedia landasan yang bisa dilakukan dewatering mudah penambalan karet, tubuh bendung terlindungi dari sengatan sinar matahari, misalnya dengan jembatan penyeberangan, tubuh bendung aman terhadap gangguan publik dan transportasi sungai, tubuh bendung tahan terhadap abrasi sedimen aman terhadap arus air dan angkutan sedimen/sampah.

\section{Dampak Positif dan Negatif Pembangunan Bendung Karet}

Keuntungan terhadap penyediaan air baku daerah pedesaan, mencegah intrusi air laut, pengendalian banjir, dan, penyediaan air irigasi. Pembangunan bendung yang melintang di sungai jika ditinjau dari segi restorasi sungai mempunyai dampak negatif bagi kehidupan biotik dan abiotik di sungai. beberapa dampak tersebut antara lain mengubah keseimbangan angkutan sedimen, merubah elevasi muka air tanah, pengurangan debit air pada sungai utama

\section{Kesimpulan}

Bendung karet berfungsi meninggikan muka air dengan cara menggembungkan tubuh bendung dan menurunkan muka air dengan cara mengempiskannya. Pembukaan bendung bisa dilakukan secara otomatis dengan pengempisan tabung karet tersebut, sedangkan pengembangannya hanya bisa dilakukan secara manual. Pemilihan jenis bahan / material yang digunakan bendung karet berisi air berpengaruh terhadap tekanan stabilitas aliran. Karakteristik bendung karet isi air di dalam negeri belum mudah untuk didapatkannya dalam pasaran bebas. Perencanaan bendung karet isi air memanfaatkan bahan geomembran sebagai wujud teknologi tepat guna.

\section{Saran.}

Pada penerapannya di lapangan banyak dijumpai berbagai masalah yang berakibat rendahnya kinerja bendung. Masalah tersebut diakibatkan oleh kurangnya dukungan teori dan pengalaman. Selain itu, belum ada pedoman yang bisa dipakai sebagai acuan untuk perencanaan bendung karet. Oleh karena itu, disusun pedoman perencanaan bendung karet. Pedoman ini memuat garis besar tentang dasar pertimbangan untuk membangun bendung karet, persyaratan lokasinya, struktur bendung karet, dan perencanaan teknis. Penanggulangan banjir dan rob solusi dengan perencanaan bendung karet yang berisi air perlu diperhatikan perhitungan stabilitas aliran, berat bendung sendiri serta faktor daya dukung tanahnya. Pemilihan 
lokasi titik bendung perlu memperhatikan kajian faktor data pendukung yang membebani aliran sungai pada bendung tersebut. Perencanaan bendung karet isi air harapannya ada peneliti yang dapat mengembangkan metode ini agar bisa membuat bendungan tanpa banyak merusak ekosistem daerah sekitar sungai. Setiap pilihan memang ada resikonya, tapi kita harus berusaha memperkecil resiko tersebut agar keseimbangan tetap terjaga.

\section{Daftar Pustaka}

[1] Abdullah Ali Nasser Alhamati, Behavior of Inflatable Dams under Hydrostatic Conditions Received: Sept 1, 2004; Revised: Nov 18, 2004; Accepted: Mar 8.

[2] Ahmad IA, A Rubber dam usage for endodontic treatment: a review. Int Endod J, 42(11),2009, pp. 963-972.

[3] Dedi Tjahjadi Abdullah, Ir, Bendung karet di Indonesia, makalah pada seminar bendung karet, 1999, Serang.

[4] Dnyaneshwari Kolte, International Conference on emerging trands in Engineering, Science and Management Rubber Dam, ISBN: 978-93-86171-32-0, 17, 2017, pp. 2933.

[5] Hidrologi teknik. Edisi Dua. Jakarta: Erlangga. Soewarno, 1995.

[6] Hidraulika II. Beta Offset. Yogyakarta. Unit Produksi dan Jasa Jurusan Teknik Sipil,2005. Penyelidikan Tanah Cone Penetrometer. Politeknik Negeri Semarang.

[7] Hill EE, Rubel BS. Do dental educators need to improve their approach to teaching rubber dam use? J Dent Educ 2008;72(10): 11771181.

[8] Hommez GM, Braem M, De Moor RJ. Root canal treatment performed by Flemish dentists, part 1: cleaning and shaping. Int Endod $\mathbf{J}$ 2003;36(3):166-173.

[9] Jenkins SM, Hayes SJ, Dummer PM. A study of endodontic treatment carried out in dental practice within the UK. Int Endod J 2001;34(1):1622.

[10] Kodoatie, R.J dan Sugiyanto, Bendung Karet Isi Udara Kali Jajar. Departemen Pekerjaan Umum, 2002, Semarang.

[11] Laporan Akhir Studi Optimasi Air Baku Bendung Gerak dan Karet Jajar. PT. Anugerah Krida Pradana. Semarang. Dirjen Pengairan Proyek Pengembangan WS Jratunseluna, 1999.

[12] Marshall K, Page J. The use of rubber dam in the UK: a survey. Br Dent J 1990;169(9):286-291.

[13] Palmer NO, Ahmed M, Grieveson B. An investigation of current endodontic practice and training needs in primary care in the north west of England. $\mathrm{Br}$ Dent $\mathrm{J}$ 2009;206(11):E22. doi:10.1038/sj.bdj. 2009.1135.

[14] Roehman Fatchur, Imam Wahyudi S. Faiqun Niam M. Analysis Of Physical Model Rubber Weir Contain Water As Motionweirfor Flood And Rob Handling. International Journal of Civil Engineering and Technology (IJCIET) Volume 10, Issue 04, April 2019, pp. 219-227, Article ID: IJCIET_10_04_024 Available onlinehttp://www.iaeme.com/ijciet/issu es.asp?JType $=$ IJCIET $\&$ VType $=10 \& I T y$ pe $=04$ ISSN Print: 0976-6308 and ISSN Online: 0976-6316 ㄷ IAEME Publication

[15] Roehman Fatchur, The Effectiveness Of Water-Filled Rubber Weir Management On Flood Mitigation Caused By Rain And "Rob" (Java Slang) In Demak District, Proceedings of International Conference : Problem, Solution and Development of Coastal and Delta Areas Semarang, Indonesia September 26th, , 2017, Paper No. C64

[16] Soldani F, Foley J. An assessment of rubber dam usage amongst specialists 
in paediatric dentistry practising within the UK. Int J Paediatr Dent 2007;17(1):50-56.

[17] Standar Perencanaan Irigasi, Kriteria Perencanaan Bangunan Utama KP02.Badan Penerbit Pekerjaan Umum. Jakarta. Direktorat Jenderal Sumber Daya Air,2005.

[18] Whitworth JM, Seccombe GV, Shoker K, Steele JG. Use of rubber dam and irrigant selection in UK general dental practice. Int Endod $\mathbf{J}$ 2000;33(5):435-441.

[19] Takasaki, M, The omata inflatable weir, at the Kawabi hydro scheme, Japan. International Water Power and Dam Construction, 41(1) 1989, pp. 39-41.

[20] Tam, P.W.M, Use of inflatable dams as agricultural weirs in Hong Kong. Journal of Hydraulic Engineering, ASCE, 124(12), 1998, pp. 1,215$1,226$.

[21] Wahyudi, S. Imam, Moh Faiqun Nieeam, and Le Bras Gilbert, Problems, Causes and Handling Analysis of Tidal Flood, Erosion and Sedimentation in Northern Coast of Central Java: Review and Recommendation, International Journal of Civil \& Environmental Engineering 12 (4) 2012, pp. 65-69. 21.

[22] River Polder System in Kudus Regency, Central Java, Indonesia." AIP Conference Proceedaings 1818. doi:10.1063/1.4976928, 2017.

[23] X.Q. Zhang, P.W.M. Tam and W. Zheng, Construction Operation and Maintenance of Rubber Dams, Canadian Journal of Civil Engineering. 29, 2002., pp. 409-420. 